\title{
Attenuation of the extracellular matrix increases the number of synapses but suppresses synaptic plasticity
}

Yulia Dembitskaya ${ }^{1}$, Nikolay Gavrilov², Igor Kraev³, Maxim Doronin ${ }^{1}$, Olga Tyurikova ${ }^{1}$, Alexey Semyanov ${ }^{1,4^{*}}$

${ }^{1}$ Department of Molecular Neurobiology, Shemyakin-Ovchinnikov Institute of Bioorganic Chemistry, Russian Academy of Sciences, Miklukho-Maklaya street 16/10, Moscow, 117997, Russia

${ }^{2}$ Lobachevsky State University of Nizhny Novgorod, Nizhny Novgorod, 603950, Russia

${ }^{3}$ Electron Microscopy Suite, Faculty of Science, Technology, Engineering and Mathematics, Open University, Milton Keynes MK7 6AA, UK

${ }^{4}$ Sechenov First Moscow State Medical University, Bolshaya Pirogovskaya str 19c1, Moscow, Russia, 119146

*Corresponding author:

Alexey Semyanov: semyanov@ibch.ru 


\section{Abstract}

The brain extracellular matrix (ECM) is a proteoglycan complex that occupies the extracellular space between brain cells and regulates brain development, brain wiring, and synaptic plasticity. However, the action of the ECM on synaptic plasticity remains controversial. Here, we employed serial section electron microscopy to show that enzymatic attenuation of ECM with chondroitinase $A B C(C h A B C)$ triggers the appearance of new glutamatergic synapses onto thin dendritic spines of CA1 pyramidal neurons. The appearance of new synapses increased the ratio of the field excitatory postsynaptic potential (fEPSP) to presynaptic fiber volley (PrV), suggesting that these new synapses are formed on existing axonal fibers. However, both the mean miniature excitatory postsynaptic current (mEPSC) amplitude and AMPA/NMDA ratio were decreased, suggesting that ECM attenuation increased the proportion of 'unpotentiated' synapses. A higher proportion of unpotentiated synapses would be expected to promote long-term potentiation (LTP). Surprisingly, theta-burst induced LTP was suppressed by ChABC treatment. The suppression of LTP was accompanied by decreased excitability of CA1 pyramidal neurons due to the upregulation of small conductance $\mathrm{Ca}^{2+}$-activated $\mathrm{K}^{+}(\mathrm{SK})$ channels. A pharmacological blockade of SK channels restored cell excitability and, expectedly, enhanced LTP above the level of control. This enhancement of LTP was abolished by a blockade of Rho-associated protein kinase (ROCK), which is involved in the maturation of dendritic spines. Thus, ECM attenuation enables the appearance of new synapses in the hippocampus, which is compensated for by a reduction in the excitability of postsynaptic neurons, thereby preventing network overexcitation at the expense of synaptic plasticity. 
The components of the extracellular matrix (ECM) form a molecular meshwork in the extracellular space of the brain. The major components of the ECM are hyaluronic acid, chondroitin sulfate proteoglycans (CSPGs), link proteins such as hyaluronan and proteoglycan link protein 1 (HAPLN1/CRTL1), and glycoproteins such as tenascin-R, which cross-link CSPGs and stabilize ECM structure (Morawski et al., 2014). The ubiquitous localization of ECM allows it to broadly affect neuronal function, both through mechanical and electrical regulation of diffusion in the extracellular space, as well as by interacting with several transmembrane receptors and channels (Nicholson and Hrabetova, 2017).

During prenatal and early postnatal brain development, the ECM provides either adhesive or repellent cues that control cell migration and navigation of growing axons. These processes involve signaling through a diverse group of transmembrane receptors, such as integrins (WehrleHaller and Bastmeyer, 2014), ApoER2, VLDL, EphB (Bouche et al., 2013; Sharaf et al., 2013), and RPTPo (Coles et al., 2011; Lang et al., 2015). In the mature brain, a number of ECM molecules and ECM receptors trigger various biochemical cascades that regulate neuronal function (Kerrisk et al., 2014). Attenuation of the ECM in the adult brain can potentially restore the brain to an immature state and promote (re-)wiring (Bikbaev et al., 2015). Hence, manipulation of the ECM has been suggested as a way to stimulate brain repair after injury and boost brain plasticity (Burnside and Bradbury, 2014; Chao et al., 2018). Nevertheless, the role of ECM in synaptic plasticity remains controversial (Dityatev and Schachner, 2003; Senkov et al., 2014). Initial studies suggested that acute enzymatic digestion of CSPGs with chondroitinase $A B C(C h A B C)$ impaired both long-term potentiation (LTP) and depression (LTD) in the CA1 region of the hippocampus (Bukalo et al., 2001). Similarly, LTP in hippocampal CA1 neurons was reduced by a deficiency in the ECM components brevican or tenascin-R reduced (Brakebusch et al., 2002; Bukalo et al., 2001, 2007; Saghatelyan et al., 2001), as well as after acute enzymatic digestion of hyaluronic acid with hyaluronidase (Kochlamazashvili et al., 2010). Moreover, intra-hippocampal injection of hyaluronidase impaired contextual fear conditioning (Kochlamazashvili et al., 2010). These studies demonstrate that ECM attenuation may disrupt synaptic plasticity and some forms of learning and memory. On the other hand, mice deficient in CSPG phosphacan/RPTPbeta exhibit increased LTP (Niisato et al., 2005). HAPLN1 knockout mice retain high juvenile-type levels of 
ocular dominance plasticity in adulthood (Carulli et al., 2010) and exhibit enhanced long-term object recognition memory and LTD in the perirhinal cortex (Romberg et al., 2013). Similarly, recognition memory is enhanced following ChABC injection (Romberg et al., 2013). These findings suggest that genetic or enzymatic attenuation of the ECM may promote some forms of synaptic plasticity and learning.

Here, we resolve this controversy by showing that ECM attenuation with ChABC increases the number of 'plastic' glutamatergic synapses onto CA1 pyramidal neurons while at the same time reducing neuronal excitability through the upregulation of small conductance $\mathrm{Ca}^{2+}$-activated $\mathrm{K}^{+}$ (SK) channels that suppress LTP.

\section{Results}

\section{ECM attenuation increases the number of glutamatergic synapses onto CA1 pyramidal neurons}

Hippocampal slices from two mice (two slices per mouse) were treated with either ChABC or a sham solution and were used for serial section electron microscopy. Dendritic spines and axonal boutons were visually identified, manually segmented, and reconstructed in 3D (Fig. 1a,b). To avoid selection bias, the number of spines and boutons was calculated in five randomly selected block series of each 3D reconstruction (Fig. 1c,d; Fig. S1). The spines were divided into two groups: mushroom spines and thin spines. Mushroom spines, which are also known as 'memory spines,' are mature spines and reflect potentiated synapses (Bourne and Harris, 2007). Their density was not significantly affected by ChABC treatment (sham: $0.51 \pm 0.05$ spines $/ \mu \mathrm{m}^{3}, n=10$; ChABC: $0.48 \pm 0.05$ spines $/ \mu \mathrm{m}^{3}, n=10 ; p=0.7$, two-sample $t$-test; Fig. $\left.1 \mathrm{e}\right)$. Thin spines have been dubbed 'learning spines' as they correspond to synapses that can be further potentiated (Bourne and Harris, 2007). ChABC treatment significantly increased the density of thin spines (sham: $1.7 \pm 0.1$ spines $/ \mu \mathrm{m}^{3}, n=10$; ChABC: $3.0 \pm 0.2$ spines $/ \mu \mathrm{m}^{3}, n=10 ; p<0.001$, two-sample $t$-test; Fig. 1f). In addition, we observed increased density of axonal boutons in the ChABC treated slices (sham: $2.3 \pm 0.1$ boutons $/ \mu \mathrm{m}^{3}, n=10$; ChABC: $3.4 \pm 0.3$ boutons $/ \mu \mathrm{m}^{3}, n=10 ; p<0.001$, twosample $t$-test; Fig. 1g). These findings are consistent with an increase in the number of CA1 - CA3 synaptic connections following ECM attenuation. 


\section{New synapses are formed by existing axons}

New synapses can either be associated with the outgrowth of new axons or can be formed from existing fibers. To accurately determine the source of new synapses, we recorded the presynaptic fiber volley (PrV) and field (f) excitatory postsynaptic potential (EPSP) that occurred in response to extracellular stimulation of Schaffer collaterals (Fig. 2a,b). We varied the stimulus intensity and determined the relationship between the fEPSP slope and the PrV amplitude (the input-output curve). The input-output curve significantly shifted upward after ChABC treatment $(F(1,80)=$ 17.23, $p<0.001$, two-way repeated measures [RM] ANOVA; Table S1, Fig. 2c). This finding suggests that the activation of an identical number of fibers produced larger EPSPS in the postsynaptic neuron. This could be a result of existing axons making additional synapses or of the existing synapses becoming potentiated. To distinguish between these two possibilities, we recorded the miniature $(\mathrm{m})$ excitatory postsynaptic currents (EPSCs) in CA1 pyramidal neurons (Fig. 2d). ChABC treatment did not significantly change the frequency of mEPSCs (sham: $0.76 \pm 0.07 \mathrm{~Hz}, n=7$; ChABC: $0.61 \pm 0.05 \mathrm{~Hz}, n=7 ; p=0.07$, two-sample $t$-test; Fig. 2e); however, the mean mEPSC amplitude decreased (sham: $22.33 \pm 2.20$ pA, $n=7 X$; ChABC: $15.50 \pm 1.90$ pA, $n=7 ; p=0.018$, two-sample $t$-test; Fig. 2 f), suggesting that ECM attenuation does not potentiate existing glutamatergic synapses onto CA1 pyramidal neurons. Thus, the upward shift of the inputoutput curve may be explained by an increase in the number of synaptic contacts made by Schaffer collaterals onto CA1 pyramidal neurons.

\section{New synapses are unpotentiated}

The decrease seen in the mean mEPSC amplitude is consistent with the observation that unpotentiated synapses have lower quantal amplitude than potentiated ones (Kullmann and Nicoll, 1992). If the number of unpotentiated synapses increases following ChABC treatment, the ratio of AMPA receptor-mediated to NMDA receptor-mediated currents (AMPA/NMDA ratio) should decrease, reflecting the lower number of AMPA receptors in unpotentiated synapses (Kauer et al., 1988; Lu et al., 2001). Indeed, we observed a significantly smaller AMPA/NMDA ratio in ChABC treated slices (sham: $3.1 \pm 0.4, n=9$; ChABC: $1.7 \pm 0.3, n=11 ; p=0.012$, twosample $t$-test; Fig. 2g,h). 
The mechanism of spontaneous and action potential-dependent vesicular release differ (Kaeser and Regehr, 2014). To determine the mode of release that is affected by ChABC treatment, we analyzed the paired-pulse ratio (PPR) of evoked EPSCS at different inter-stimulus intervals (ISI, Fig. S2a,b). ChABC did not have a significant effect on PPR $(F(1,40)=0.36, p=0.6$, two-way RM ANOVA; Table S1, Fig. S2b), suggesting that action potential-dependent glutamate release is not affected by ECM attenuation. In addition, we characterized the lateral mobility of postsynaptic AMPA receptors in the membranes of spines. It has been reported that hyaluronidase-mediated attenuation of ECM accelerates the lateral diffusion of postsynaptic AMPA receptors in cultured neurons (Frischknecht et al., 2009). Accelerated movement of AMPA receptors allows for quick replacement of receptors that have been desensitized by synaptic glutamate uncaging and therefore expediates the recovery of the AMPA receptor-mediated current. However, the pairedpulse depression of the glutamate uncaging-induced AMPA receptor currents did not change significantly after ChABC treatment (sham: $0.91 \pm 0.04, n=7 ;$ ChABC: $0.92 \pm 0.03, n=7 X$; $p=0.99$, two-sample $t$-test, Fig. S2c-e). This suggests that ECM attenuation in hippocampal slices does not affect the lateral diffusion of AMPA receptors.

\section{ECM attenuation suppresses LTP}

The appearance of additional unpotentiated synapses after ChABC treatment should increase the magnitude of LTP. To test this, we recorded EPSPs in CA1 pyramidal neurons and induced LTP by 5 episodes of theta-burst stimulation of Schaffer collaterals (TBS, Fig. 3a). Surprisingly, LTP was not enhanced but completely suppressed after ChABC treatment (sham: $181 \pm 22 \%$ of baseline, $n=8$; ChABC: $109 \pm 12 \%$ of baseline, $n=6 ; p=0.013$, two-sample $t$-test; Fig. 3b,c). To understand the mechanism of such suppression, we analyzed cellular responses to individual, ten-burst episodes of theta-burst stimulation (Fig. 3d). In sham-treated slices, we observed a progressive increase in the number of action potentials from the first to the fifth episode. In the first episode, the number of action potentials in ChABC-treated slices was indistinguishable from that in the sham; however, from the second episode onward, the number of action potentials in the ChABCtreated slices was reduced when compared to sham slices $(F(1,500)=183.58, p<0.001$, two-way RM ANOVA; Table S1, Fig. 3e). Similar changes were observed in the slope of burst EPSPs. The 
slope progressively increased during subsequent theta-bursts in the sham-treated slices, but this progressive increase was not apparent after ChABC treatment $(F(1,500)=278.44, p<0.001$, twoway RM ANOVA; Table S1, Fig. 3f).

LTP can be influenced by GABAergic inhibition (Chapman et al., 1998; Grover and Yan, 1999), which may increase upon ECM attenuation (Hirono et al., 2018). ChABC treatment did not produce significant changes in the frequency or amplitude of spontaneous and miniature IPCSs (Fig. S3a-f). Likewise, no significant effect was observed on the PPR of evoked IPSCs (Fig. S3g,h). Thus, ECM attenuation did not affect the basal properties of GABAergic synaptic transmission. However, GABAergic signaling may respond differently to theta-burst stimulation. Theta-burst stimulation did not result in the potentiation of IPSCs in CA1 pyramidal neurons (Fig. S4a-C). Lastly, we monitored changes to IPSCs during individual episodes of theta-burst stimulation (Fig. S4d). No significant changes were observed in the normalized IPSP amplitudes after ChABC treatment (Fig. S4e).

\section{ECM attenuation reduces the excitability of CA1 pyramidal neurons through upregulation of SK} channels

The suppression of LTP may indicate that ChABC treatment reduces the excitability of postsynaptic neurons. Indeed, ChABC treatment significantly reduced the number of action potentials evoked in CA1 pyramidal neurons following 500 ms current injections. $(F(1,100)=$ 21.99, $p<0.001$, two-way RM ANOVA; Table S1, Fig. 4a,b). This effect of ECM attenuation remained even after the blockade of glutamatergic and GABAergic ionotropic receptors with 50 $\mu \mathrm{M}$ APV, $50 \mu \mathrm{M}$ NBQX, and $100 \mu \mathrm{M}$ picrotoxin (Fig. S5). No significant change in the input resistance $\left(R_{\text {in }}\right)$ of cells was observed after ChABC treatment (sham: $R_{\text {in }}=172 \pm 20 M \Omega, n=6$, ChABC: $\mathrm{R}_{\text {in }}=162 \pm 17 \mathrm{M} \Omega, n=6 ; p=0.82$, two-sample $t$-test; Fig. $4 \mathrm{c}$ and $\left.\mathrm{S} 5 \mathrm{c}, \mathrm{f}\right)$. Therefore, tonic conductances mediated by extrasynaptic receptors or plasma membrane channels are not involved in reducing the excitability of pyramidal neurons following ChABC treatment. The observed decrease in cell excitability could be associated with the downregulation of voltagegated $\mathrm{Na}^{+}$channels or the upregulation of voltage-gated $\mathrm{K}^{+}$channels which would then affect the waveform and threshold of action potentials. However, neither the action potential threshold 
(sham: $-44.5 \pm 1.5 \mathrm{mV}, n=6$; ChABC: $-46.2 \pm 0.8 \mathrm{mV}, n=6 ; p=0.94$, two-sample $t$-test) nor the action potential half-width (sham: $1.49 \pm 0.18 \mathrm{~ms}, n=6$; ChABC: $1.55 \pm 0.15 \mathrm{~ms}, n=6 ; p=0.81$, two-sample $t$-test) were affected by ChABC treatment (Fig. S6). An after hyperpolarization (AHP) of increased magnitude is another possible mechanism behind the reduced excitability. Indeed, ChABC treatment significantly increased the AHP recorded in response to an injection of depolarizing current $(F(1,100)=25.96, p<0.001$, two-way RM ANOVA; Table S1, Fig. 4d).

Several types of $\mathrm{Ca}^{2+}$-activated $\mathrm{K}^{+}$channels contribute to the AHP (Savic et al., 2001). First, we measured the current mediated by small conductance $\mathrm{Ca}^{2+}$-activated $\mathrm{K}^{+}$(SK) channels (IsK). We recorded an outward current following a depolarizing step (50 ms, $70 \mathrm{mV}$ ) in the presence of 1 $\mu \mathrm{M}$ tetrodotoxin, a $\mathrm{Na}^{+}$channel blocker. Then we applied $100 \mathrm{nM}$ apamin, an SK channel blocker, and thus obtained the remaining, non-SK channel-mediated outward current (InonSk). We obtained $I_{s k}$ by subtracting Inonsk from the total current. ChABC treatment significantly increased Isk (sham: $9.2 \pm 2.7 \mathrm{pA}, n=6$; ChABC: $30.7 \pm 5.7 \mathrm{pA}, n=7 ; p=0.003$, two-sample $t$-test; Fig. 4e,f) but had no significant effect on Inonsk (sham: $64.3 \pm 18.3$ pA, $n=6$; ChABC: $50.7 \pm 10.8$ pA, $n=7$; $p=0.36$, two-sample $t$-test; Fig. 4g,h). Thus, ECM attenuation upregulates SK channels but does not upregulate other $\mathrm{Ca}^{2+}$-activated $\mathrm{K}^{+}$channels. This rules out the possible involvement of voltage-dependent $\mathrm{Ca}^{2+}$ channels (Kochlamazashvili et al., 2010), as it would affect all $\mathrm{Ca}^{2+}$ activated $\mathrm{K}^{+}$channels.

Next, we tested if the upregulation of SK channels is responsible for the reduced excitability of CA1 pyramidal neurons following ChABC treatment. Apamin abolished both the decrease in cell excitability (cell firing in apamin: $F(1,100)=0.01, p=0.9$, two-way RM ANOVA; Table S1, Fig. 4i,j) and AHP amplification (AHP in apamin: $F(1,108)=0.41, p=0.5$, two-way RM ANOVA; Table S1, Fig. $4 \mathrm{k}, \mathrm{l})$ induced by ChABC treatment. Consistent with the lack of contribution of other $\mathrm{Ca}^{2+}$ activated $\mathrm{K}^{+}$channels, the decrease in cell excitability induced by ChABC treatment was preserved in the presence of $5 \mu \mathrm{M}$ paxilline, a blocker of large conductance $\mathrm{Ca}^{2+}$-activated $\mathrm{K}^{+}$(BK) channels (cell firing in paxilline: $F(8,72)=13.40, p<0.001$, two-way RM ANOVA; Table S1,Fig. S7) 


\section{Blockade of SK channels reveals enhanced LTP upon ECM attenuation}

Next, we tested if a blockade of SK channels could also rescue the suppression of LTP after ChABC treatment. In agreement with the increased proportion of unpotentiated synapses, LTP was not only rescued, but significantly enhanced in the presence of apamin (sham + apamin: $155 \pm 9 \%$ of baseline, $n=8$; ChABC + apamin: $266 \pm 31 \%$ of baseline, $n=7 ; p=0.003$, two-sample $t$-test; Fig. 5a-c). Notably, the number of action potentials and the increased EPSP slope during theta burst stimulation were rescued, but not enhanced, by apamin (number of action potentials: $F(1,600)=$ 3.17, $p=0.08$, two-way RM ANOVA; increase in EPSP slope: $F(1,600)=0.97, p=0.33$, two-way RM ANOVA; Table S1, Fig. 5e,d).

If the enhanced LTP can be attributed to the enlargement of thin spines, it should be associated with pathways involved in cytoskeletal remodeling. These pathways require activation of small GTPases, such as RhoA (Murakoshi et al., 2011). RhoA controls spine remodeling through Rhoassociated protein kinase (ROCK) (Nakayama et al., 2000). Indeed, the ROCK inhibitor Y-27632 $(10 \mu \mathrm{M})$ abolished the enhancement of LTP observed in ChABC treated slices in the presence of apamin (sham + apamin + Y-27632: $182.8 \pm 41.4 \%$ of baseline, $n=7 ;$ ChABC + apamin + Y-27632: $213.8 \pm 31.0 \%$ of baseline, $n=7 ; p=0.56$, two-sample $t$-test; Fig. $5 f-h)$. The number of action potentials and the increased EPSP slope during theta burst stimulation were not affected by the ROCK inhibitor (number of action potentials: $F(1,600)=1.81, p=0.18$; increase in EPSP slope: $F(1,600)=2.93, p=0.1$, two-way RM ANOVA; Table S1, Fig. 5i,j). Thus, the observed LTP consisted of two components: ROCK-dependent and ROCK-independent LTP. The ROCK-dependent component is linked to spine enlargement and is promoted by ECM attenuation.

\section{Discussion}

The ECM holds neighboring cells together and stabilizes synapses (Dansie and Ethell, 2011; Levy et al., 2014). However, the ECM also shields the cell surface making it more difficult for new synapses to form (Bikbaev et al., 2015; Orlando et al., 2012). The effect of ECM removal on dendritic spines has been previously shown in neuronal culture and organotypic slices, where it increases spine motility, spine extension, and network rewiring (Bikbaev et al., 2015). Physiologically, the ECM is quite diffuse at early developmental stages, allowing for neuronal 
network wiring and rewiring (Frischknecht and Gundelfinger, 2012). In the adult brain, the ECM stabilizes existing dendritic spines and restricts the appearance of new ones. Hence, the morphological plasticity of dendritic spines and synaptic rewiring requires activity-dependent recruitment of multiple extracellular proteases, such as ADAMTS4/5/15, MMP9, and neurotrypsin, that produce localized degradation of ECM (Bijata et al., 2017; Ferrer-Ferrer and Dityatev, 2018). Injection of ChABC has been demonstrated to promote axonal sprouting in the pericontusion cortical region in vivo (Harris et al., 2010). In this study, we observed that the ECM attenuation induced by ChABC triggers the formation of new synapses between existing axons and new thin dendritic spines in the hippocampus.

The thin dendritic spines that appear upon ECM attenuation are 'learning spines.' The name indicates the ability of these spines to undergo further morphological maturation during synaptic enhancement and conversion to mushroom or 'memory' spines (Bourne and Harris, 2007). Mushroom spines host more AMPA receptors, which makes their synapses stronger (Matsuzaki et al., 2001; Nimchinsky et al., 2004). Smaller spines with thinner necks exhibit a larger increase in $\mathrm{Ca}^{2+}$ concentration during LTP induction; hence, they are more likely to be potentiated (Noguchi et al., 2005). During LTP, new AMPA receptors get inserted into the postsynaptic density (PSD) (Bredt and Nicoll, 2003; Malinow and Malenka, 2002). Both the spine and PSD increase in size, leading to spine 'maturation' (Bosch et al., 2014).

Our morphological observations did not reveal any significant changes in the density of mushroom spines after ChABC treatment. Electrophysiologically, we found that both the mean amplitude of mEPSC and the AMPA/NMDA ratio decreased. Thus, ECM attenuation increased the proportion of unpotentiated thin spines. This would be expected to enhance LTP, as the magnitude of LTP depends on the ratio of unpotentiated to potentiated synapses (Govindarajan et al., 2011; McNaughton and Morris, 1987); surprisingly, LTP was suppressed in ChABC treated slices. This LTP suppression could not be attributed to changes in the efficiency of glutamatergic or GABAergic synaptic transmission following ECM attenuation. mEPSC frequency; the pairedpulse ratio of evoked EPSCs; sIPSC/mIPSC frequency and amplitude; and the PPR of evoked IPSCS appeared to be unchanged after ChABC treatment. It has been reported that ECM limits lateral 
diffusion of AMPA receptors along the plasma membrane and hence regulates synaptic strength in neuronal cultures (Favuzzi et al., 2017; Frischknecht et al., 2009). However, we did not find evidence that attenuation of ECM with ChABC affects the lateral diffusion of AMPA receptors in hippocampal slices. This finding is consistent with another report which suggested that the ECM does not regulate the lateral diffusion of AMPA receptors in aspiny neurons (Klueva et al., 2014).

We hypothesized that increased membrane conductance and decreased postsynaptic neuron excitability may be responsible for the observed suppression of LTP. The ECM protein vitronectin regulates inactivating potassium currents $\left(I_{A}\right)$ in embryonic mouse hippocampal neurons (Vasilyev and Barish, 2003); brevican controls the localization of potassium channels in parvalbumin-positive interneurons (Favuzzi et al., 2017); and hyaluronic acid regulates hippocampal synaptic plasticity by modulating postsynaptic L-type $\mathrm{Ca}^{2+}$ channels (Kochlamazashvili et al., 2010). In this study, ChABC treatment decreased the excitability of CA1 pyramidal neurons. This decrease was not accompanied by any change in action potential threshold or waveform, ruling out an effect of ECM attenuation on $\mathrm{Na}^{+}$or $\mathrm{K}^{+}$channels. The input resistance of cells was likewise unaffected, indicating a lack of effect on baseline membrane conductances. The reduced excitability of CA1 pyramidal neurons was mediated by the upregulation of SK channels. Indeed, SK channels are known to cause early spike frequency adaptation and contribute to AHP in CA1 pyramidal neurons (Chen et al., 2014). SK channels have also been reported to curtail $\mathrm{Ca}^{2+}$ influx in dendritic spines and shafts during neuronal firing and to reduce synaptic plasticity (Griffith et al., 2016; Jones and Stuart, 2013; Jones et al., 2017). The SK channel blocker apamin increases LTP and facilitates learning (Adelman et al., 2012). Here, an application of apamin restored both the excitability of cells and LTP that were suppressed by ECM attenuation.

It is unknown if the upregulation of SK channels can be mediated directly by ECM attenuation. Currently, there is no evidence that components of the ECM interact with SK channels. However, SK channels are directly coupled to NMDA receptors in dendritic spines (Luján et al., 2009). Thus, the appearance of new dendritic spines may potentially increase the total number of SK channels in the neuron. In other words, each dendritic spine adds a 'quantum' of SK channels, progressively 
decreasing the excitability of the cell. In fact, during cerebellar development, the formation of new synapses is associated with a progressive increase in the expression of SK channels in Purkinje cells (Ballesteros-Merino et al., 2014). It is possible that the upregulation of SK channels alongside an increase in the number of excitatory synapses serves as a protective mechanism against overexcitation of the neuronal network, which can lead to excitotoxicity and epilepsy. A similar mechanism has been revealed during LTP induction in CA1 pyramidal neurons, where LTP triggers upregulation of hyperpolarization-activated cation $(h)$ channels, thereby decreasing overall cell excitability and balancing the additional excitation stemming from increased synaptic strength (Fan et al., 2005; Wu et al., 2012). Thus, in order to maintain network stability, CA1 pyramidal neurons possess mechanisms to balance the excitability associated with increased synaptic strength and/or an increased number of excitatory synapses.

During LTP induction, thin dendritic spines undergo morphological changes that require remodeling of the cytoskeleton and actin polymerization (Fukazawa et al., 2003; Krucker et al., 2000; Okamoto et al., 2004). First, $\mathrm{Ca}^{2+}$ enters through NMDARs and voltage-gated $\mathrm{Ca}^{2+}$ channels and then activates $\mathrm{Ca}^{2+}$ /calmodulin kinase II (CaMK II) (Bosch et al., 2014; Furuyashiki et al., 2002). Next, CaMK II activates the RhoA-ROCK pathway, which controls the enlargement of spines (Hedrick et al., 2016; Murakoshi et al., 2011; Rex et al., 2009). The upregulation of SK channels reduces $\mathrm{Ca}^{2+}$ influx during LTP induction and prevents activation of this pathway (Griffith et al., 2016). When SK channels were blocked with apamin, the full strength of LTP was unleashed. Consistent with a higher proportion of unpotentiated synapses, the magnitude of LTP was increased by ECM attenuation. Blocking ROCK abolished the enhancement of LTP in ChABC treated slices, suggesting that the mechanism behind this enhancement is related to the potentiation of synapses on thin spines. However, the ROCK blockade did not completely abolish LTP. This finding suggests that a certain amount of LTP is independent of the RhoA-ROCK pathway and that this form of LTP is not affected by ECM attenuation.

In summary, we conclude that ECM suppresses the growth of new spines in hippocampal pyramidal neurons (Fig.6). When the ECM is attenuated by exogenous treatment or by endogenous metalloproteinases new synaptic contacts are formed on thin dendritic spines. The 
appearance of new spines parallels the upregulation of SK channels that leads to reduced excitability of neurons and suppresses LTP. This phenomenon may represent a mechanism of neuronal network stabilization but may also lead to impaired learning and memory.

\section{Methods}

\section{Animals}

All experiments were performed in 4- to 6-week-old C57BL/6J mice. Animal procedures were conducted in accordance with regulations and ethical animal research standards defined by the ethical committee of the Lobachevsky State University of Nizhny Novgorod.

\section{Hippocampal slice preparation}

Animals were killed by cervical dislocation and then decapitated. The brains were exposed and chilled with ice-cold solution containing (in mM) $87 \mathrm{NaCl}, 2.5 \mathrm{KCl}, 7 \mathrm{MgCl}_{2}, 1.25 \mathrm{NaH}_{2} \mathrm{PO}_{4}, 26.2$ $\mathrm{NaHCO}_{3}, 0.5 \mathrm{CaCl}_{2}, 25 \mathrm{D}$-glucose, and 50 sucrose. Hippocampi from both hemispheres were isolated, and $350 \mu \mathrm{m}$-thick transverse slices were cut with a vibrating microtome (Microm HM 650V, Thermo Fisher Scientific, or VT1200S, Leica). Slices were incubated in a 3-ml chamber for 2 hours at $37^{\circ} \mathrm{C}$ in a solution containing (in $\mathrm{mM}$ ) $113 \mathrm{NaCl}, 2.38 \mathrm{KCl}, 1.24 \mathrm{MgSO}_{4}, 0.95 \mathrm{NaH}_{2} \mathrm{PO}_{4}$, 24.9 $\mathrm{NaHCO}_{3}, 1 \mathrm{CaCl}_{2}, 1.6 \mathrm{MgCl}_{2}, 27.8 \mathrm{D}$-glucose and $0.2 \%$ bovine serum albumin (sham) or in the same solution supplemented with $0.2 \mathrm{U} / \mathrm{ml}$ of protease-free chondroitinase $A B C(C h A B C)$ from Proteus vulgaris (Amsbio, UK). Next, the slices were transferred to a recording chamber and were continuously perfused with a solution containing (in mM) $119 \mathrm{NaCl}, 2.5 \mathrm{KCl}, 1.3 \mathrm{MgSO}_{4}, 1$ $\mathrm{NaH}_{2} \mathrm{PO}_{4}, 26.2 \mathrm{NaHCO}_{3}, 2.5 \mathrm{CaCl}_{2}$, and $11 \mathrm{D}$-glucose. All solutions were saturated with $95 \% \mathrm{O}_{2}$ and $5 \% \mathrm{CO}_{2}$. The osmolarity was $295 \pm 5 \mathrm{mOsm}$.

\section{Electron microscopy}

Acute slices of two animals were treated with either sham or ChABC solutions and were placed into a solution containing 3\% paraformaldehyde and $0.5 \%$ glutaraldehyde in $0.1 \mathrm{M} \mathrm{Na-cacodylate}$ buffer ( $\mathrm{pH}$ 7.2-7.4) at room temperature. The slices were further fixed for electron microscopy by immersion in $2.5 \%$ glutaraldehyde in the same $0.1 \mathrm{M} \mathrm{Na}$-cacodylate buffer for $24 \mathrm{~h}$. The tissue 
was postfixed with $1 \%$ osmium tetroxide and $0.01 \%$ potassium dichromate in the same buffer for 1-2 $\mathrm{h}$ at room temperature. The tissue was then dehydrated in graded aqueous solutions of ethanol from $40 \%$ to $96 \%$ (each for $10 \mathrm{~min}$ ) and then $100 \%$ acetone (three changes, each for 10 $\mathrm{min})$. Specimens were infiltrated with a mixture of 50\% epoxy resin and 50\% pure acetone for 30 min at room temperature. Each slice was placed on an Aclar film and covered with a capsule containing pure epoxy resin (Epon 812/AralditeM epoxy resins) at $60^{\circ} \mathrm{C}$ for $1 \mathrm{~h}$ and polymerized overnight at $80^{\circ} \mathrm{C}$. The epoxy resin blocks with tissue slices were coded and all further analyses were carried out by an investigator blinded to the experimental status of the tissue. The embedded slices on the block surface were trimmed with a glass knife along the entire surface of the hippocampal slice, and 1- $\mu \mathrm{m}$ thick sections were cut. A trapezoidal area was prepared with a glass knife with one side of 250-350 $\mu \mathrm{m}$ in length, and that included the CA1 hippocampal area. Images of serial sections (60 nm) were cut with a Diatome diamond knife and allowed to form a ribbon on the surface of a water/ethanol solution ( $2 \%-5 \%$ ethanol in water) in the knife bath and collected using Pioloform-coated slot copper grids. Sections were counterstained with saturated ethanolic uranyl acetate, followed by lead citrate, and then placed in a rotating grid holder to allow for the uniform orientation of sections on adjacent grids in the electron microscope. Serial sections in the middle of the stratum radiatum at a location $~ 125-150 \mu \mathrm{m}$ from the CA1 pyramidal cell body layer were obtained at a magnification of 4000x in a JEOL 1010 electron microscope. Each image was around 20.8 by $11.2 \mu \mathrm{m}^{2}$. Up to 150 serial sections per series were photographed for reconstruction.

\section{Stereological and 3D reconstruction analysis}

Images in the series were aligned automatically using homemade software. Further analysis was done in Reconstruct software (http://synapseweb.clm.utexas.edu/software-0). The unbiased brick method (Fiala and Harris, 2001) was used for correct sampling from the total synapse population being presented in the acquired volume of CA1 stratum radiatum. Each image stack was divided into 5 parts, 30 sections in depth. Unbiased bricks $2 \mu \mathrm{m} \times 2 \mu \mathrm{m}$ in size and 10 sections $(0.6 \mu \mathrm{m})$ in depth were positioned randomly into each part of the image stack using a sampling grid of X: $8 \mu \mathrm{m}, \mathrm{Y}: 6 \mu \mathrm{m}$ in size. In total, 30 unbiased bricks were analyzed (Fig.S1). Three sides of the brick were inclusion planes, and the other three sides were exclusion planes. Postsynaptic 
densities (PSD) were used as markers for dendritic spines. Those PSDs that were completely inside the brick or touching only the inclusion planes were counted, whereas PSDs that made any contact with the exclusion planes were excluded. All countable dendritic spines, their PSDs, and presynaptic boutons were traced and generated meshed 3D objects, of which the volume and surface area figures were used for further morphological analysis. Approximately 120-180 spines/PSDs were reconstructed per animal. 3D reconstructions of the selected dendritic spines were imported to 3D Studio Max 2016 software for rendering and subsequent rotation to display the optimal view of the reconstructed structures.

\section{Electrophysiology}

Presynaptic fiber volley (PrV) and field EPSP (fEPSP) were simultaneously recorded with a glass electrode ( 3 - $5 \mathrm{M} \Omega$ resistance) filled with the extracellular solution and placed in CA1 stratum radiatum (field rec. at Fig. 2a). Stimulation of Schaffer collaterals was performed with a bipolar stainless-steel electrode (FHC, Bowdoinham, ME, USA) at a distance of more than $150 \mu \mathrm{m}$ from the recording site (stim. at Fig. 2a). The amplitude of the baseline stimulation frequency was $0.05 \mathrm{~Hz}$, which induced a half-maximal response. The stimulus intensity was varied to obtain the relationship between the fEPSP slope and PrV amplitude (the input-output curve). PrV amplitudes were binned with $0.05 \mathrm{mV}$ bin size in the range from 0 to $0.45 \mathrm{mV}$ and the mean fEPSP slope was calculated for each bin.

Whole-cell recordings from CA1 pyramidal neurons were obtained with glass electrodes (3-5 M $\Omega$ resistance). mEPSCs were recorded using an intracellular solution containing (in $\mathrm{mM}$ ): 130 $\mathrm{KCH}_{3} \mathrm{SO}_{3}, 8 \mathrm{NaCl}, 10 \mathrm{Na}$ phosphocreatine, 10 HEPES, 2 EGTA, $3 \mathrm{Na}$ L-ascorbic acid, $10 \mathrm{HEPES}, 0.4$ NaGTP, 2 MgATP, and $5 \mathrm{QX314} \mathrm{Br}$ (pH adjusted to 7.2 with $\mathrm{KOH}$ and osmolarity adjusted to 290 mOsm. ). The membrane potential was clamped at $-70 \mathrm{mV}$. The extracellular solution contained $100 \mu \mathrm{M}$ picrotoxin, $200 \mu \mathrm{M}$ (S)-a-methyl-4-carboxyphenyglycine (MCPG), 5 MM CGP52432 and 1 $\mu \mathrm{M}$ tetrodotoxin to block $\mathrm{GABA}_{A}, \mathrm{mGluR}_{\mathrm{R}}, \mathrm{GABA} \mathrm{B}_{B}$ receptors and action potentials, respectively.

Spontaneous inhibitory postsynaptic currents (SIPSCs) were recorded using pipette solution containing (in mM): $120 \mathrm{CsCl}, 8 \mathrm{NaCl}, 0.2 \mathrm{MgCl}_{2}, 10 \mathrm{HEPES}, 2 \mathrm{EGTA}, 0.3 \mathrm{NaGTP}, 2 \mathrm{MgATP}$, and 5 Qx314 $\mathrm{Br}$ (pH adjusted to 7.2 with $\mathrm{CsOH}$ and osmolarity adjusted to $290 \mathrm{mOsm}$ ). The membrane 
potential was clamped at $-70 \mathrm{mV}$. The extracellular solution contained $50 \mu \mathrm{M}$ APV, $25 \mu \mathrm{M}$ NBQX, $200 \mu \mathrm{M}$ MCPG, and $5 \mu \mathrm{M}$ CGP52432 to block NMDA, AMPA, mGluR, and GABA $\mathrm{B}_{\mathrm{B}}$ receptors, respectively. For mIPSCs recordings, $1 \mu \mathrm{M}$ tetrodotoxin was added to this drug cocktail. Schaffer collaterals were stimulated at 20,50,100, and 150 ms interstimulus intervals to measure the PPR of the evoked IPSCs.

EPSCs mediated by AMPA (EPSC AMPA $_{\text {) and NMDA (EPSC }}$ NMDA) receptors were recorded using an intracellular solution containing (in $\mathrm{mM}$ ): $130 \mathrm{KCH}_{3} \mathrm{SO}_{3}, 8 \mathrm{NaCl}, 10 \mathrm{Na}$ phosphocreatine, $10 \mathrm{HEPES}$, 2 EGTA, $3 \mathrm{Na}$ L-ascorbic acid, 10 HEPES, 0.4 NaGTP, 2 MgATP, and 5 QX314 Br (pH adjusted to 7.2 with $\mathrm{KOH}$ and osmolarity adjusted to $290 \mathrm{mOsm}$ ) in $\mathrm{Mg}^{2+}$ free extracellular solution in the presence of $100 \mu \mathrm{M}$ picrotoxin, $200 \mu \mathrm{M}$ MCPG, and $5 \mu \mathrm{M}$ CGP52432. The membrane potential was clamped at $-70 \mathrm{mV}$. In this set of experiments, CA3-CA1 connections were cut to prevent over-excitation. Shaffer collaterals were stimulated using extracellular bipolar microelectrodes. The stimulation strength was adjusted to evoke composite EPSCs with amplitudes of 300 pA,

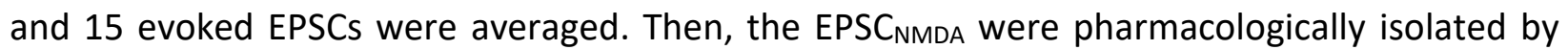

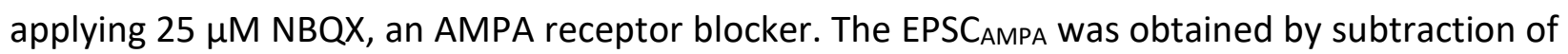
EPSC $_{\text {NMDA }}$ from the composite EPSC. The AMPA/NMDA ratio was calculated as a ratio of EPSC AMPA $_{\text {A }}$ to PPSC $_{\text {NMDA }}$ amplitudes. The EPSC paired-pulse ratio was obtained at several inter-pulse intervals under the same conditions but without NBQX and in the presence of $\mathrm{Mg}^{2+}$ in the extracellular solution.

Cell excitability was measured using a pipette solution containing (in mM) $140 \mathrm{~K}$-gluconate, 8 $\mathrm{NaCl}, 0.2 \mathrm{CaCl}_{2}, 10 \mathrm{HEPES}, 2 \mathrm{EGTA}, 0.5 \mathrm{NaGTP}$, and $2 \mathrm{MgATP}$ (pH adjusted to 7.2 with $\mathrm{KOH}$ and osmolarity adjusted to $290 \mathrm{mOsm}$ ). Membrane potential was manually adjusted at $-70 \mathrm{mV}$ in current-clamp mode, and 500-ms current steps were injected with increasing amplitudes from 80 pA to 440 pA in steps of 40 pA. The first steps which did not trigger action potentials (-80 pA to +80 pA range) were used to plot IV-curves (not presented) and calculate the cell input resistance using Ohm's law. The action potential threshold and half-width were obtained at the first current steps at which action potentials appeared (rheobase). The threshold was calculated as the value of the membrane potential corresponding to the speed of change of the membrane 
potential $\left(\Delta \mathrm{V}_{\mathrm{m}} / \Delta \mathrm{t}\right)$ of $20 \mathrm{mV} / \mathrm{ms}$. Half-width was calculated as the duration of the action potential at the voltage halfway between the threshold and the action potential peak. The afterhyperpolarization (AHP) was calculated as the amplitude of a negative peak after a $500 \mathrm{~ms}$ depolarizing step relative to the baseline before the depolarizing step.

$I_{s k}$ and $I_{n o n s k}$ were measured with intracellular solution containing (in $\mathrm{mM}$ ) $140 \mathrm{~K}$-gluconate, 8 $\mathrm{NaCl}, 0.2 \mathrm{CaCl}_{2}, 10 \mathrm{HEPES}, 2 \mathrm{EGTA}, 0.5 \mathrm{NaGTP}$, and $2 \mathrm{MgATP}$ (pH adjusted to 7.2 with $\mathrm{KOH}$ and osmolarity adjusted to $290 \mathrm{mOsm}$ ) in the presence of $1 \mu \mathrm{M}$ tetrodotoxin. Membrane potential was clamped at $-70 \mathrm{mV}$, and $500 \mathrm{~ms}$ depolarizing steps to $+40 \mathrm{mV}$ were delivered to induce potassium current. Isk was blocked and Inonsk was pharmacologically isolated with $100 \mathrm{nM}$ apamin. Then, $I_{\text {nonsk }}$ was subtracted from the total potassium current to obtain $I_{\text {sk. }}$.

\section{Long-term potentiation (LTP)}

LTP was recorded in single neurons in current-clamp mode with glass electrodes filled with intracellular solution containing (in $\mathrm{mM}$ ): $132.5 \mathrm{~K}$ gluconate, $8 \mathrm{NaCl}, 10 \mathrm{Na}$ phosphocreatine, 10 HEPES, $3 \mathrm{Na}$ L-ascorbic acid, $0.5 \mathrm{NaGTP}$, and $2 \mathrm{MgATP}$ (pH adjusted to 7.2 with $\mathrm{KOH}$ and osmolarity adjusted to $290 \mathrm{mOsm}$ ). Membrane potential was manually adjusted to $-70 \mathrm{mV}$. The stimulation strength was adjusted to obtain EPSP amplitudes in the range of 5-7 mV. Theta-burst stimulation (TBS) was applied five times (at $0.2 \mathrm{~Hz}$ ) to induce LTP and consisted of 4 stimuli at 100 $\mathrm{Hz}$ delivered 10 times at $5 \mathrm{~Hz}$. The baseline recording lasted 10 min before TBS. LTP was recorded for 40 min after TBS. The mean EPSP slope recorded before TBS was taken as $100 \%$. LTP values were calculated from 30 to 40 min after TBS.

The effect of TBS on evoked IPSCS was recorded with a pipette solution containing (in $\mathrm{mM}$ ): 130 $\mathrm{CsCH}_{3} \mathrm{SO}_{3}, 8 \mathrm{NaCl}, 10 \mathrm{Na}$ phosphocreatine, 10 HEPES, 2 EGTA, $3 \mathrm{Na}$ L-ascorbic acid, 10 HEPES, 0.4 NaGTP, 2 MgATP, and $5 \mathrm{QX314} \mathrm{Br}$ (pH adjusted to 7.2 with $\mathrm{KOH}$ and osmolarity adjusted to 290 mOsm). No glutamate receptor blockers were added to the extracellular solution. The membrane potential was clamped at the reversal potential of glutamatergic currents, $0 \mathrm{mV}$. TBS was applied five times at $0.2 \mathrm{~Hz}$. 


\section{Two-photon imaging and glutamate uncaging}

Cells were filled with $50 \mu \mathrm{M}$ Alexa 594 for at least 10 min prior to recordings to ensure uniform diffusion of the dye. Two-photon imaging was performed with a two-scanner FV1000-MPE laserscanning microscope (Olympus, Japan) equipped with a mode-locked (<140 fs pulse width) tunable 720-930 nm laser Chameleon XR (Coherent, USA). Alexa 594 was excited at a wavelength of $830 \mathrm{~nm}$ and its fluorescence was chromatically separated and detected with a photomultiplier (PMTs). The bright Alexa Fluor 594 emission identified oblique apical dendrites (about $150 \mathrm{~mm}$ from the soma) and their spines. $600 \mu \mathrm{M}$ of 4-methoxy-7-nitroindolinyl-caged-Lglutamate (MNI-caged-L-glutamate;) was added to the bath for glutamate uncaging. Singlephoton uncaging was carried out using 5-10 ms laser pulses (405 nm diode laser; FV5-LD405; Olympus, Japan) with "point scan" mode in Fluoview (Olympus). The uncaging spot was located at the edge of the spine head. The strength of uncaging was adjusted to achieve an uncaginginduced synaptic current amplitude of 150-250 pA. AMPA current (I $\left.\mathrm{I}_{\mathrm{AMPA}}\right)$ was recorded in the presence of $50 \mu \mathrm{M}$ APV. The desensitization of AMPA receptors was tested as IAMPA PPR with a $100 \mathrm{~ms}$ interpulse interval.

\section{Drugs and chemicals}

All drugs were kept as concentrated stock solutions at $-20^{\circ} \mathrm{C}$. Apamin, paxilline, CGP55845, Y27632 were added from the beginning of experiments. MNI-caged glutamate was applied $10 \mathrm{~min}$ before the recording. Picrotoxin, MCPG, D-APV, NBQX, tetrodotoxin, CGP55845, apamin, paxilline, and MNI-caged glutamate were purchased either from Tocris Cookson (Bristol, UK) or Sigma Aldrich (Darmstadt, Germany). Y-27632 (10 $\mu \mathrm{M})$ was added to sham- and ChABC-treated slices during the whole incubation period. Alexa Fluor 594 was obtained from Invitrogen (Carlsbad, CA, USA).

\section{Data Analysis}

Electrophysiological data were analyzed using WinWCP, Mini analysis (6.0.2, Synaptosoft, USA), and Clampfit (9.0 Axon Instruments Inc.; Union City, CA, USA). Statistical analysis was performed with Excel (Microsoft, USA), Origin 8 (OriginLab Corp.), SigmaPlot (12.3 Systat Software Inc., USA), 
and Matlab 2012b (The MathWorks Inc., USA). All data are presented as the mean \pm SEM, and differences between groups were tested with unpaired $t$-test and two-way RM ANOVA, as stated in the text. $p>0.05$ was considered significant.

\section{Acknowledgments}

The authors are grateful to Prof. Alexander Dityatev for valuable comments, Dr Inseon Song for help with electrophysiology experiments and Ms Inna Golyagina for help with analysis of electron microscopy images.

Author contributions: Y.D., M.D., and O.T. conducted the electrophysiological experiments, N.G. and I.K. analyzed the electron microscopy data, Y.D., N.G., and A.S. performed statistical analysis and prepared the figures, Y.D. and A.S. wrote the manuscript; A.S. designed the experiments; all authors edited the manuscript.

Competing interests: The authors declare that they have no competing interests.

Data and materials availability: All data needed to evaluate the conclusions in the article are present in the article and/or supplementary materials. Additional data related to this article may be requested from the authors. 


\section{References}

Adelman, J.P., Maylie, J., and Sah, P. (2012). Small-Conductance Ca2+-Activated K+ Channels: Form and Function. Annual Review of Physiology 74, 245-269.

Ballesteros-Merino, C., Martínez-Hernández, J., Aguado, C., Watanabe, M., Adelman, J.P., and Luján, R. (2014). Localization of SK2 channels relative to excitatory synaptic sites in the mouse developing Purkinje cells. Frontiers in Neuroanatomy 8.

Bijata, M., Labus, J., Guseva, D., Stawarski, M., Butzlaff, M., Dzwonek, J., Schneeberg, J., Böhm, K., Michaluk, P., Rusakov, D.A., et al. (2017). Synaptic Remodeling Depends on Signaling between Serotonin Receptors and the Extracellular Matrix. Cell Reports 19, 1767-1782.

Bikbaev, A., Frischknecht, R., and Heine, M. (2015). Brain extracellular matrix retains connectivity in neuronal networks. Scientific Reports 5, 14527.

Bosch, M., Castro, J., Saneyoshi, T., Matsuno, H., Sur, M., and Hayashi, Y. (2014). Structural and Molecular Remodeling of Dendritic Spine Substructures during Long-Term Potentiation. Neuron 82, 444-459.

Bouche, E., Romero-Ortega, M.I., Henkemeyer, M., Catchpole, T., Leemhuis, J., Frotscher, M., May, P., Herz, J., and Bock, H.H. (2013). Reelin induces EphB activation. Cell research 23, 473490.

Bourne, J., and Harris, K.M. (2007). Do thin spines learn to be mushroom spines that remember? Curr Opin Neurobiol 17, 381-386.

Brakebusch, C., Seidenbecher, C.I., Asztely, F., Rauch, U., Matthies, H., Meyer, H., Krug, M., Bockers, T.M., Zhou, X., Kreutz, M.R., et al. (2002). Brevican-deficient mice display impaired hippocampal CA1 long-term potentiation but show no obvious deficits in learning and memory. Molecular and cellular biology 22, 7417-7427.

Bredt, D.S., and Nicoll, R.A. (2003). AMPA receptor trafficking at excitatory synapses. Neuron 40, 361-379.

Bukalo, O., Schachner, M., and Dityatev, A. (2001). Modification of extracellular matrix by enzymatic removal of chondroitin sulfate and by lack of tenascin-R differentially affects several forms of synaptic plasticity in the hippocampus. Neuroscience 104, 359-369.

Bukalo, O., Schachner, M., and Dityatev, A. (2007). Hippocampal metaplasticity induced by deficiency in the extracellular matrix glycoprotein tenascin-R. The Journal of neuroscience : the official journal of the Society for Neuroscience 27, 6019-6028.

Burnside, E.R., and Bradbury, E.J. (2014). Review: Manipulating the extracellular matrix and its role in brain and spinal cord plasticity and repair. Neuropathology and Applied Neurobiology 40, 26-59.

Carulli, D., Pizzorusso, T., Kwok, J.C., Putignano, E., Poli, A., Forostyak, S., Andrews, M.R., Deepa, S.S., Glant, T.T., and Fawcett, J.W. (2010). Animals lacking link protein have attenuated perineuronal nets and persistent plasticity. Brain : a journal of neurology 133, 2331-2347. 
Chao, M.V., Warren, P.M., Dickens, S.M., Gigout, S., Fawcett, J.W., and Kwok, J.C.F. (2018). Regulation of CNS Plasticity Through the Extracellular Matrix. (Oxford University Press).

Chapman, C.A., Perez, Y., and Lacaille, J.-C. (1998). Effects of GABAA inhibition on the expression of long-term potentiation in CA1 pyramidal cells are dependent on tetanization parameters. Hippocampus 8, 289-298.

Chen, S., Benninger, F., and Yaari, Y. (2014). Role of Small Conductance Ca $<$ sup $>2+</$ sup $>-$ Activated $\mathrm{K}<$ sup $>+</$ sup $>$ Channels in Controlling CA1 Pyramidal Cell Excitability. The Journal of Neuroscience 34, 8219-8230.

Coles, C.H., Shen, Y., Tenney, A.P., Siebold, C., Sutton, G.C., Lu, W., Gallagher, J.T., Jones, E.Y., Flanagan, J.G., and Aricescu, A.R. (2011). Proteoglycan-specific molecular switch for RPTPsigma clustering and neuronal extension. Science 332, 484-488.

Dansie, L.E., and Ethell, I.M. (2011). Casting a net on dendritic spines: the extracellular matrix and its receptors. Developmental neurobiology 71, 956-981.

Dityatev, A., and Schachner, M. (2003). Extracellular matrix molecules and synaptic plasticity. Nature reviews Neuroscience 4, 456-468.

Fan, Y., Fricker, D., Brager, D.H., Chen, X., Lu, H.C., Chitwood, R.A., and Johnston, D. (2005). Activity-dependent decrease of excitability in rat hippocampal neurons through increases in I(h). Nature neuroscience 8, 1542-1551.

Favuzzi, E., Marques-Smith, A., Deogracias, R., Winterflood, C.M., Sánchez-Aguilera, A., Mantoan, L., Maeso, P., Fernandes, C., Ewers, H., and Rico, B. (2017). Activity-Dependent Gating of Parvalbumin Interneuron Function by the Perineuronal Net Protein Brevican. Neuron 95, 639655.e610.

Ferrer-Ferrer, M., and Dityatev, A. (2018). Shaping Synapses by the Neural Extracellular Matrix. Frontiers in Neuroanatomy 12.

Fiala, J.C., and Harris, K.M. (2001). Extending unbiased stereology of brain ultrastructure to threedimensional volumes. J Am Med Inform Assoc 8, 1-16.

Frischknecht, R., and Gundelfinger, E.D. (2012). The brain's extracellular matrix and its role in synaptic plasticity. Adv Exp Med Biol 970, 153-171.

Frischknecht, R., Heine, M., Perrais, D., Seidenbecher, C.I., Choquet, D., and Gundelfinger, E.D. (2009). Brain extracellular matrix affects AMPA receptor lateral mobility and short-term synaptic plasticity. Nature neuroscience 12, 897.

Fukazawa, Y., Saitoh, Y., Ozawa, F., Ohta, Y., Mizuno, K., and Inokuchi, K. (2003). Hippocampal LTP is accompanied by enhanced F-actin content within the dendritic spine that is essential for late LTP maintenance in vivo. Neuron 38, 447-460.

Furuyashiki, T., Arakawa, Y., Takemoto-Kimura, S., Bito, H., and Narumiya, S. (2002). Multiple spatiotemporal modes of actin reorganization by NMDA receptors and voltage-gated $\mathrm{Ca} 2+$ channels. Proceedings of the National Academy of Sciences of the United States of America 99, 14458-14463. 
Govindarajan, A., Israely, I., Huang, S.-Y., and Tonegawa, S. (2011). The Dendritic Branch Is the Preferred Integrative Unit for Protein Synthesis-Dependent LTP. Neuron 69, 132-146.

Griffith, T., Tsaneva-Atanasova, K., and Mellor, J.R. (2016). Control of Ca2+ Influx and Calmodulin Activation by SK-Channels in Dendritic Spines. PLOS Computational Biology 12, e1004949.

Grover, L.M., and Yan, C. (1999). Blockade of GABAA Receptors Facilitates Induction of NMDA Receptor-Independent Long-Term Potentiation. Journal of neurophysiology 81, 2814-2822.

Harris, N.G., Mironova, Y.A., Hovda, D.A., and Sutton, R.L. (2010). Chondroitinase ABC enhances pericontusion axonal sprouting but does not confer robust improvements in behavioral recovery. J Neurotrauma 27, 1971-1982.

Hedrick, N.G., Harward, S.C., Hall, C.E., Murakoshi, H., McNamara, J.O., and Yasuda, R. (2016). Rho GTPase complementation underlies BDNF-dependent homo- and heterosynaptic plasticity. Nature 538, 104-108.

Hirono, M., Watanabe, S., Karube, F., Fujiyama, F., Kawahara, S., Nagao, S., Yanagawa, Y., and Misonou, H. (2018). Perineuronal Nets in the Deep Cerebellar Nuclei Regulate GABAergic Transmission and Delay Eyeblink Conditioning. The Journal of Neuroscience 38, 6130-6144.

Jones, S.L., and Stuart, G.J. (2013). Different calcium sources control somatic versus dendritic SK channel activation during action potentials. The Journal of neuroscience : the official journal of the Society for Neuroscience 33, 19396-19405.

Jones, S.L., To, M.-S., and Stuart, G.J. (2017). Dendritic small conductance calcium-activated potassium channels activated by action potentials suppress EPSPs and gate spike-timing dependent synaptic plasticity. eLife 6, e30333.

Kaeser, P.S., and Regehr, W.G. (2014). Molecular mechanisms for synchronous, asynchronous, and spontaneous neurotransmitter release. Annual review of physiology 76, 333-363.

Kauer, J.A., Malenka, R.C., and Nicoll, R.A. (1988). A persistent postsynaptic modification mediates long-term potentiation in the hippocampus. Neuron 1, 911-917.

Kerrisk, M.E., Cingolani, L.A., and Koleske, A.J. (2014). ECM receptors in neuronal structure, synaptic plasticity, and behavior. Prog Brain Res 214, 101-131.

Klueva, J., Gundelfinger, E.D., Frischknecht, R.R., and Heine, M. (2014). Intracellular $\mathrm{Ca}^{2+}$ and not the extracellular matrix determines surface dynamics of AMPA-type glutamate receptors on aspiny neurons. Philosophical transactions of the Royal Society of London Series B, Biological sciences 369, 20130605.

Kochlamazashvili, G., Henneberger, C., Bukalo, O., Dvoretskova, E., Senkov, O., Lievens, P.M., Westenbroek, R., Engel, A.K., Catterall, W.A., Rusakov, D.A., et al. (2010). The extracellular matrix molecule hyaluronic acid regulates hippocampal synaptic plasticity by modulating postsynaptic L-type Ca(2+) channels. Neuron 67, 116-128.

Krucker, T., Siggins, G.R., and Halpain, S. (2000). Dynamic actin filaments are required for stable long-term potentiation (LTP) in area CA1 of the hippocampus. Proceedings of the National Academy of Sciences of the United States of America 97, 6856-6861. 
Kullmann, D.M., and Nicoll, R.A. (1992). Long-term potentiation is associated with increases in quantal content and quantal amplitude. Nature 357, 240-244.

Lang, B.T., Cregg, J.M., DePaul, M.A., Tran, A.P., Xu, K., Dyck, S.M., Madalena, K.M., Brown, B.P., Weng, Y.L., Li, S., et al. (2015). Modulation of the proteoglycan receptor PTPsigma promotes recovery after spinal cord injury. Nature 518, 404-408.

Levy, A.D., Omar, M.H., and Koleske, A.J. (2014). Extracellular matrix control of dendritic spine and synapse structure and plasticity in adulthood. Frontiers in Neuroanatomy 8.

Lu, W.-Y., Man, H.-Y., Ju, W., Trimble, W.S., MacDonald, J.F., and Wang, Y.T. (2001). Activation of Synaptic NMDA Receptors Induces Membrane Insertion of New AMPA Receptors and LTP in Cultured Hippocampal Neurons. Neuron 29, 243-254.

Luján, R., Maylie, J., and Adelman, J.P. (2009). New sites of action for GIRK and SK channels. Nature Reviews Neuroscience 10, 475-480.

Malinow, R., and Malenka, R.C. (2002). AMPA receptor trafficking and synaptic plasticity. Annu Rev Neurosci 25, 103-126.

Matsuzaki, M., Ellis-Davies, G.C., Nemoto, T., Miyashita, Y., lino, M., and Kasai, H. (2001). Dendritic spine geometry is critical for AMPA receptor expression in hippocampal CA1 pyramidal neurons. Nature neuroscience 4, 1086-1092.

McNaughton, B.L., and Morris, R.G.M. (1987). Hippocampal synaptic enhancement and information storage within a distributed memory system. Trends in neurosciences 10, 408-415.

Morawski, M., Dityatev, A., Hartlage-Rubsamen, M., Blosa, M., Holzer, M., Flach, K., Pavlica, S., Dityateva, G., Grosche, J., Bruckner, G., and Schachner, M. (2014). Tenascin-R promotes assembly of the extracellular matrix of perineuronal nets via clustering of aggrecan. Philosophical transactions of the Royal Society of London Series B, Biological sciences 369, 20140046.

Murakoshi, H., Wang, H., and Yasuda, R. (2011). Local, persistent activation of Rho GTPases during plasticity of single dendritic spines. Nature 472, 100-104.

Nakayama, A.Y., Harms, M.B., and Luo, L. (2000). Small GTPases Rac and Rho in the Maintenance of Dendritic Spines and Branches in Hippocampal Pyramidal Neurons. The Journal of Neuroscience 20, 5329-5338.

Nicholson, C., and Hrabetova, S. (2017). Brain Extracellular Space: The Final Frontier of Neuroscience. Biophys J 113, 2133-2142.

Niisato, K., Fujikawa, A., Komai, S., Shintani, T., Watanabe, E., Sakaguchi, G., Katsuura, G., Manabe, T., and Noda, M. (2005). Age-dependent enhancement of hippocampal long-term potentiation and impairment of spatial learning through the Rho-associated kinase pathway in protein tyrosine phosphatase receptor type Z-deficient mice. The Journal of neuroscience : the official journal of the Society for Neuroscience 25, 1081-1088.

Nimchinsky, E.A., Yasuda, R., Oertner, T.G., and Svoboda, K. (2004). The number of glutamate receptors opened by synaptic stimulation in single hippocampal spines. The Journal of neuroscience : the official journal of the Society for Neuroscience 24, 2054-2064. 
Noguchi, J., Matsuzaki, M., Ellis-Davies, G.C., and Kasai, H. (2005). Spine-neck geometry determines NMDA receptor-dependent Ca2+ signaling in dendrites. Neuron 46, 609-622.

Okamoto, K., Nagai, T., Miyawaki, A., and Hayashi, Y. (2004). Rapid and persistent modulation of actin dynamics regulates postsynaptic reorganization underlying bidirectional plasticity. Nature neuroscience 7, 1104-1112.

Orlando, C., Ster, J., Gerber, U., Fawcett, J.W., and Raineteau, O. (2012). Perisynaptic chondroitin sulfate proteoglycans restrict structural plasticity in an integrin-dependent manner. The Journal of neuroscience : the official journal of the Society for Neuroscience 32, 18009-18017, 18017a.

Rex, C.S., Chen, L.Y., Sharma, A., Liu, J., Babayan, A.H., Gall, C.M., and Lynch, G. (2009). Different Rho GTPase-dependent signaling pathways initiate sequential steps in the consolidation of longterm potentiation. The Journal of cell biology 186, 85-97.

Romberg, C., Yang, S., Melani, R., Andrews, M.R., Horner, A.E., Spillantini, M.G., Bussey, T.J., Fawcett, J.W., Pizzorusso, T., and Saksida, L.M. (2013). Depletion of perineuronal nets enhances recognition memory and long-term depression in the perirhinal cortex. The Journal of neuroscience : the official journal of the Society for Neuroscience 33, 7057-7065.

Saghatelyan, A.K., Dityatev, A., Schmidt, S., Schuster, T., Bartsch, U., and Schachner, M. (2001). Reduced perisomatic inhibition, increased excitatory transmission, and impaired long-term potentiation in mice deficient for the extracellular matrix glycoprotein tenascin-R. Molecular and cellular neurosciences 17, 226-240.

Savic, N., Pedarzani, P., and Sciancalepore, M. (2001). Medium afterhyperpolarization and firing pattern modulation in interneurons of stratum radiatum in the CA3 hippocampal region. Journal of neurophysiology 85, 1986-1997.

Senkov, O., Andjus, P., Radenovic, L., Soriano, E., and Dityatev, A. (2014). Neural ECM molecules in synaptic plasticity, learning, and memory. Prog Brain Res 214, 53-80.

Sharaf, A., Bock, H.H., Spittau, B., Bouche, E., and Krieglstein, K. (2013). ApoER2 and VLDLr are required for mediating reelin signalling pathway for normal migration and positioning of mesencephalic dopaminergic neurons. PloS one 8, e71091.

Vasilyev, D.V., and Barish, M.E. (2003). Regulation of an inactivating potassium current (IA) by the extracellular matrix protein vitronectin in embryonic mouse hippocampal neurones. J Physiol $547,859-871$.

Wehrle-Haller, B., and Bastmeyer, M. (2014). Intracellular signaling and perception of neuronal scaffold through integrins and their adapter proteins. Prog Brain Res 214, 443-460.

Wu, Y.-W., Grebenyuk, S., McHugh, T.J., Rusakov, D.A., and Semyanov, A. (2012). Backpropagating Action Potentials Enable Detection of Extrasynaptic Glutamate by NMDA Receptors. Cell Reports 1, 495-505. 
a

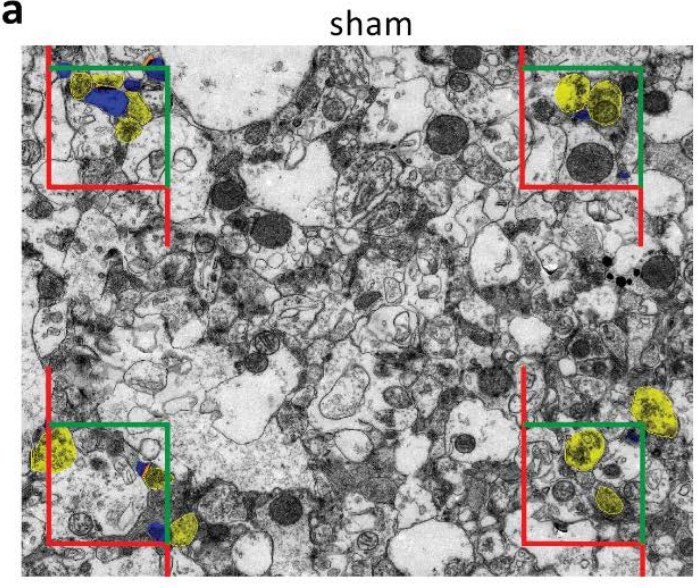

b

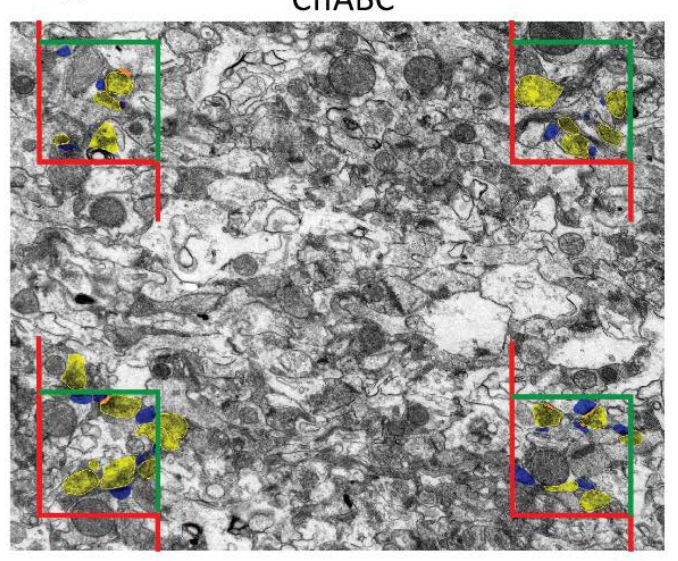

d
C

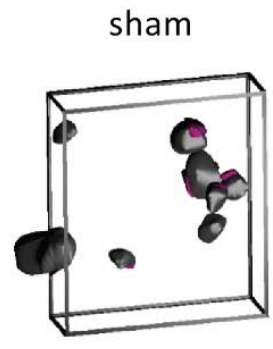

e

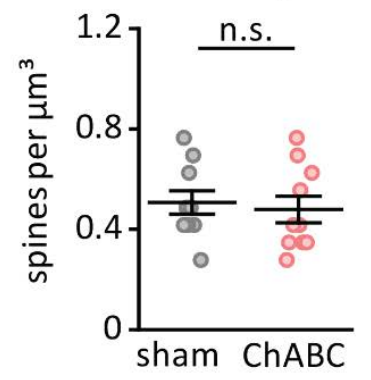

ChABC
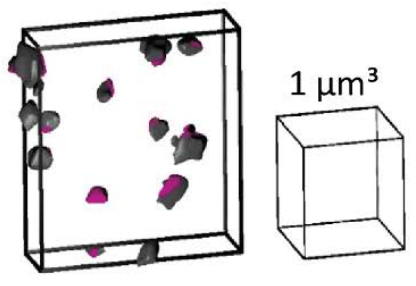

f thin spines

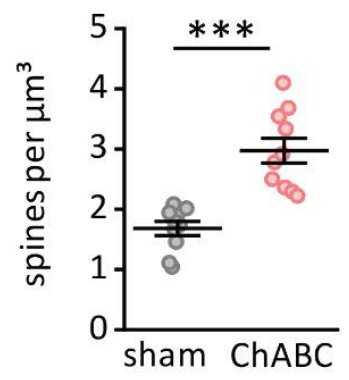

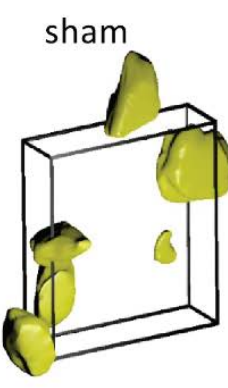

ChABC

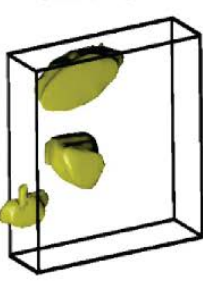

g

axonal boutons

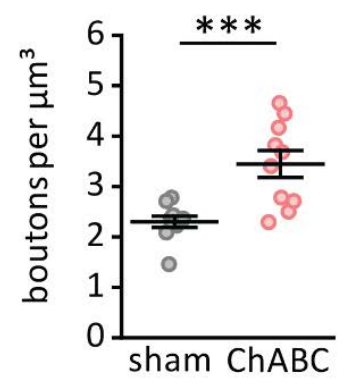

Figure 1. ECM attenuation increases the number of glutamatergic synapses onto CA1 pyramidal neurons

a,b. Electron microscopy images from sham-treated $(a)$ and ChABC-treated $(b)$ slices showing dendritic spines (blue), axonal boutons (yellow) and postsynaptic densities (orange) within and at the borders of unbiased bricks. Green sides of the bricks are inclusive, red sides are exclusive (see Methods section). c,d. Examples of 3D reconstructed dendritic spines (c) and axonal boutons (d) analyzed in the unbiased bricks within the samples. Left box - sham, right box - ChABC. e,f,g. Summary plot of mushroom spine $(e)$, thin spine $(f)$, and axonal bouton $(g)$ densities in 10 boxes from 2 sham-treated slices (black circles) and 2 slices treated with ChABC (pink circles).

The data are presented as the mean \pm SEM. n.s. $p>0.05 ; * * * p<0.001$; two-tailed two-sample $t$-test 

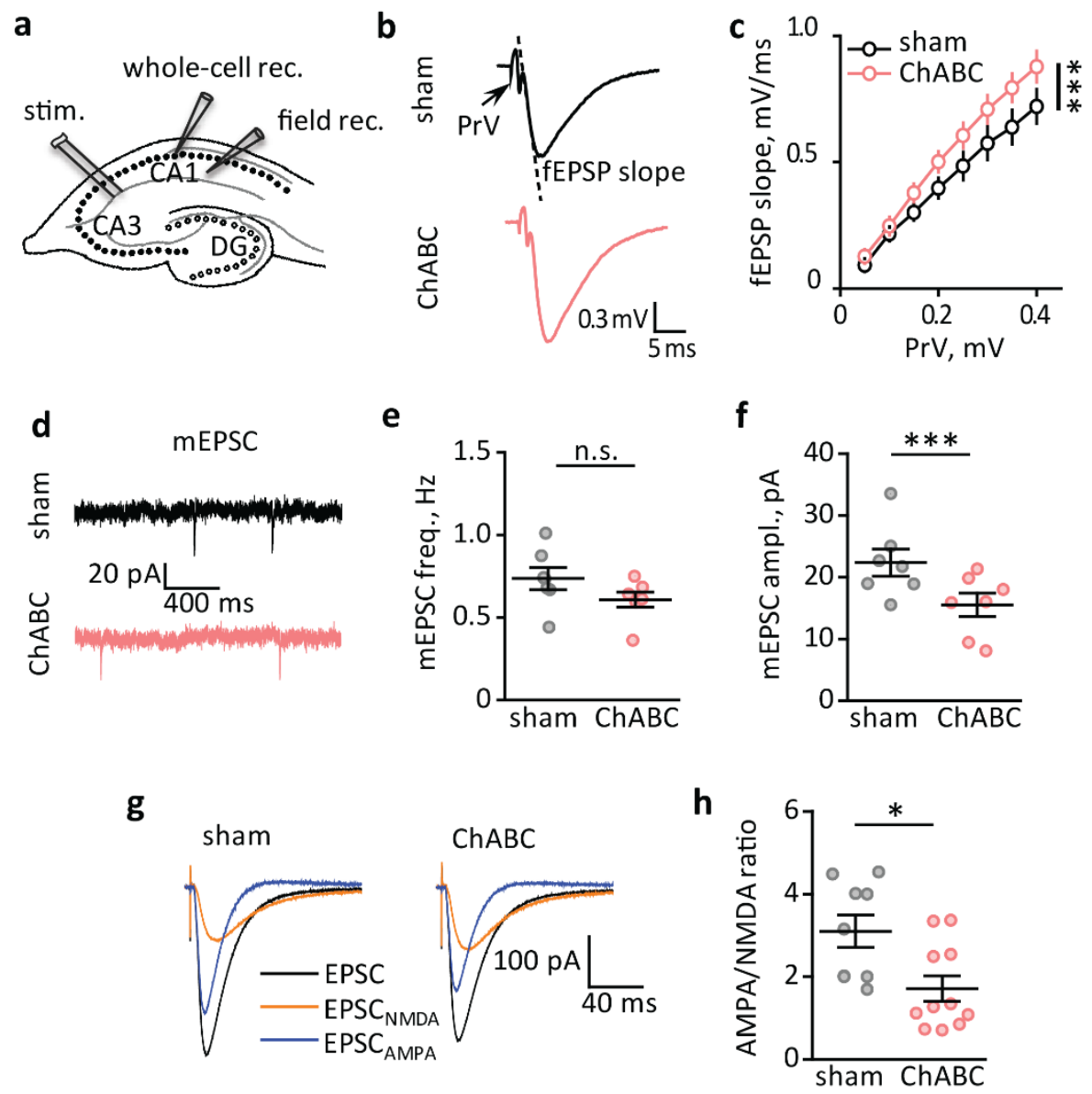

Figure 2. New unpotentiated synapses are formed by existing axons

a. Position of the recording and stimulating electrodes in the CA1 region of hippocampal slices. A stimulating electrode (stim.) was placed in the stratum radiatum at the border of CA1 to activate Schaffer collaterals. Whole-cell recordings were performed with one stimulating electrode (whole-cell rec.) from CA1 pyramidal neurons. Field potential recordings (PrV and fEPSP) were obtained with an extracellular glass electrode (field rec.) placed at the CA1 stratum radiatum. b. Representative traces of field potentials (PrV and fEPSP). Arrow points to PrV. The dashed line indicates the fEPSP slope. c. The averaged input-output curves or relationships of fEPSP slope to PrV amplitude. d. Representative traces of mEPSCs. e,f. Summary of the mIPSC frequency $(e)$ and mean amplitude $(f)$. g. Evoked EPSCs were recorded in $\mathrm{Mg}^{2+}$ free extracellular solution. At baseline conditions, EPSCs consisted of AMPA and NMDA receptor mediated components (EPSC, black trace). Application of NBQX blocked AMPA receptors and revealed

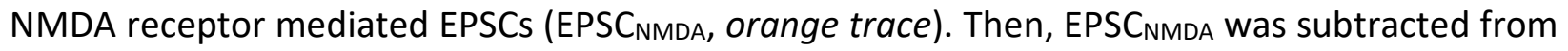
EPSC to obtain the AMPA receptor mediated EPSC (EPSC ${ }_{A M P A}$, blue trace). $\mathbf{h}$. The ratio of the EPSC $_{\text {AMPA }}$ to EPSC $_{\text {NMDA }}$ amplitude.

Black traces and circles - recordings in sham-treated slices; pink traces and circles - recordings in ChABC-treated slices. The data are presented as the mean \pm SEM. n.s. $p>0.05 ; * p<0.05$; $* * * p<0.001$; two-way RM ANOVA (panel $c$ ); two-tailed two-sample $t$-test (panels $e, f, h$ ). 
a

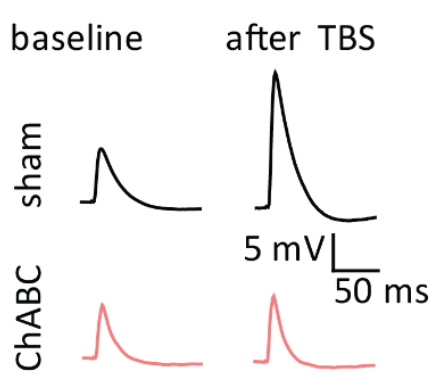

d

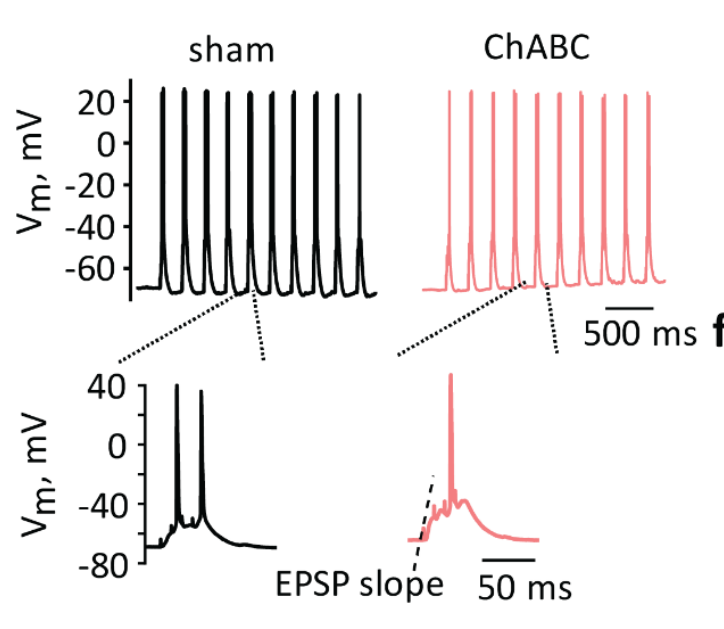

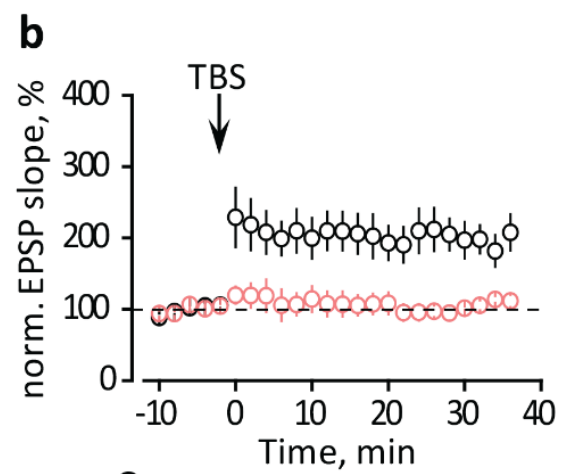

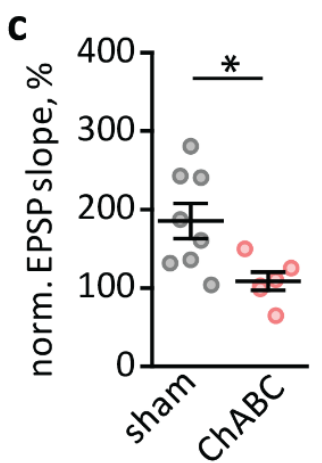

e
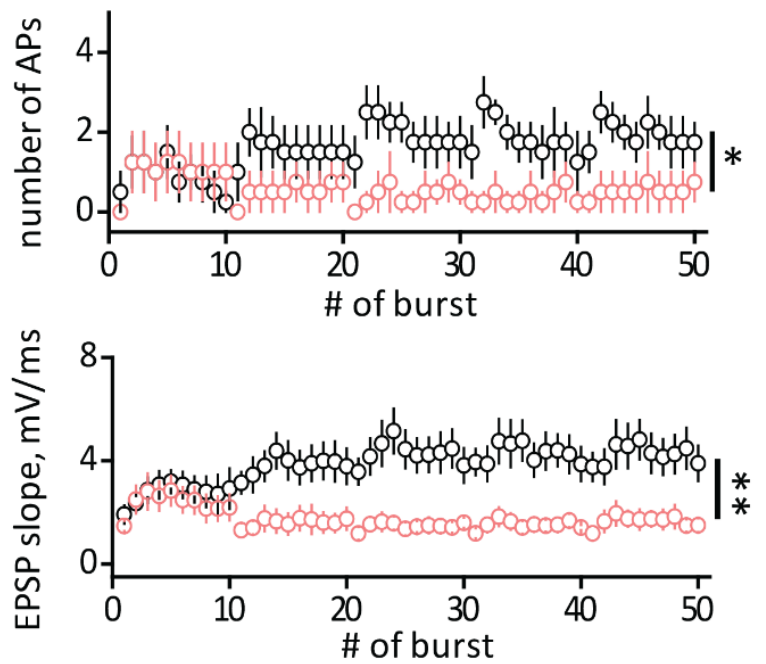

\section{Figure 3. ECM attenuation suppresses LTP}

a. EPSPs recorded in CA1 pyramidal neurons before (baseline) and after TBS. $\mathbf{b}$. The time-course of normalized EPSP slopes before and after TBS (arrow, zero time point). c. LTP magnitudes were averaged over the last $10 \mathrm{~min}$ of recordings presented in $b$. d. Cell responses to TBS (first 10 bursts out of 5 repetitions). Insets show the response to a single burst. The dashed line indicates where the EPSP slope was measured. e,f. The number of action potentials (APs, e) and EPSP slope $(f)$ recorded in response to individual bursts during TBS used to induce LTP ( 5 series by 10 bursts).

Black traces and circles - recordings in sham-treated slices; pink traces and circles - recordings in ChABC-treated slices. The data are presented as the mean \pm SEM. n.s. $p>0.05 ; * p<0.05$; ${ }^{* *} p<0.01$; two-tailed two-sample $t$-test (panel $c$ ); two-way RM ANOVA (panels $e, f$ ). 
a

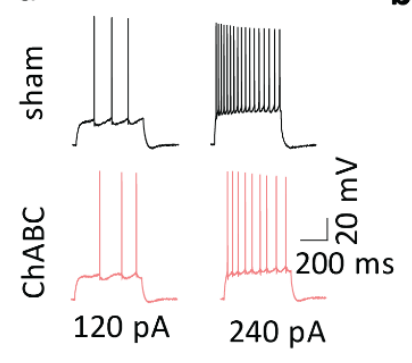

e
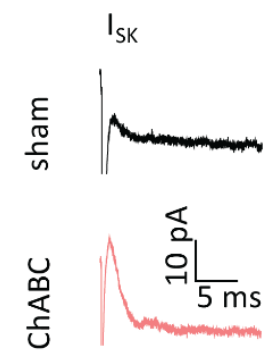

i

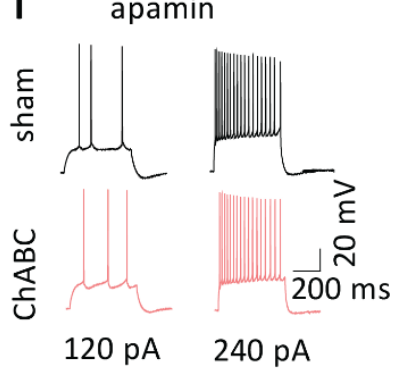

b

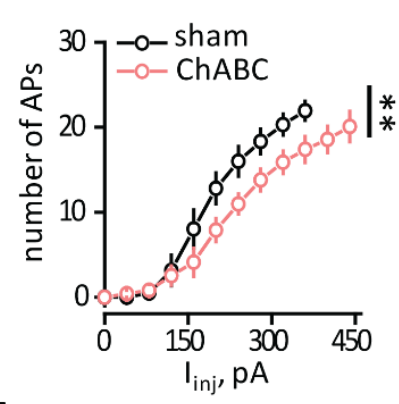

f

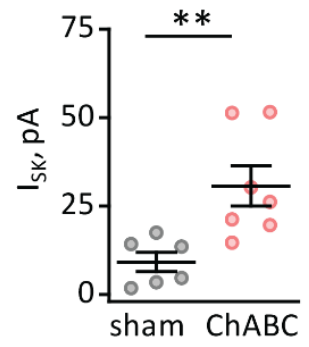

j

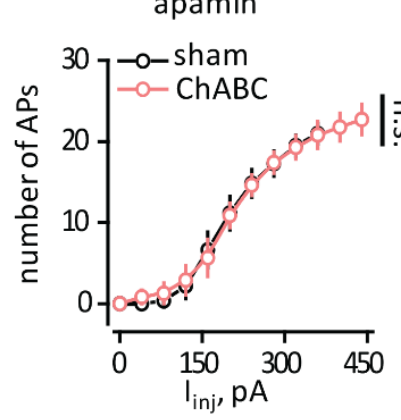

C

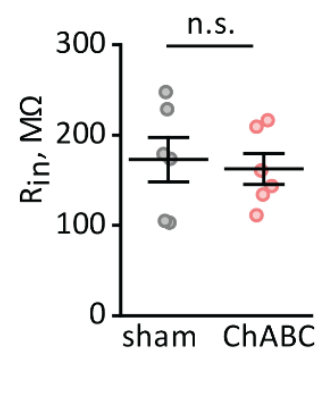

g

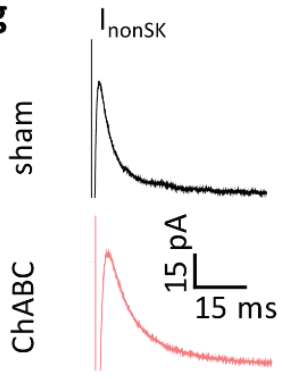

$\mathbf{k}$

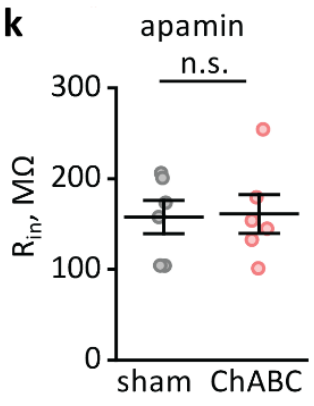

d

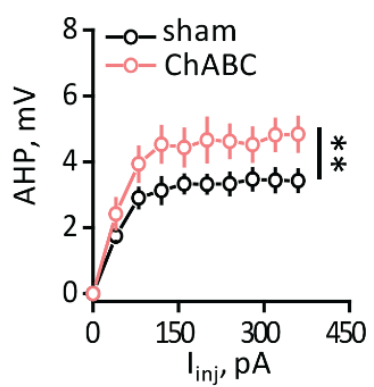

h

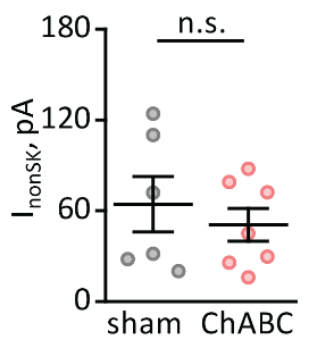

I apamin

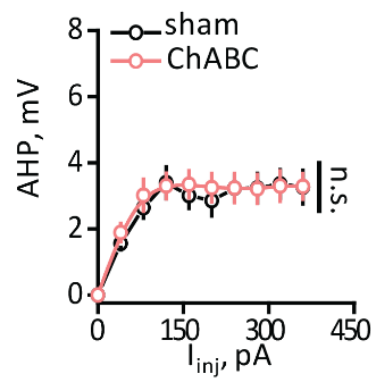

Figure 4. ECM attenuation reduces the excitability of CA1 pyramidal neurons through upregulation of SK channels

a. Action potentials elicited by depolarizing current steps ( 120 pA and 240 pA). b. Summary of the number of action potentials (APs) that occur in response to depolarizing steps. c. Summary of the input resistance $\left(R_{\text {in }}\right)$. d. Summary of AHP amplitudes. e. Representative traces of Isk. $f$. Summary of Isk amplitudes. g. Representative traces of Inonsk. $\mathbf{h}$. Summary of Inonsk amplitudes. $\mathbf{i}$. Action potentials (APs) elicited by depolarizing current steps (120 pA and $240 \mathrm{pA}$ ) in the presence of the SK channel blocker, apamin. j. Summary of the number of APs that occur in response to depolarizing steps in the presence of apamin. k. Summary of $R_{\text {in }}$ in the presence of apamin. $\mathbf{I}$. Summary of AHP amplitude in the presence of apamin.

Black traces and circles - recordings in sham-treated slices; pink traces and circles - recordings in ChABC-treated slices. The data are presented as the mean \pm SEM. n.s. $p>0.05$; ${ }^{* *} p<0.01$; twoway RM ANOVA (panels $b, d, j, l)$; two-tailed two-sample $t$-test (panels $c, f, h, k$ ). 
a

$$
\text { apamin }
$$

baseline after TBS
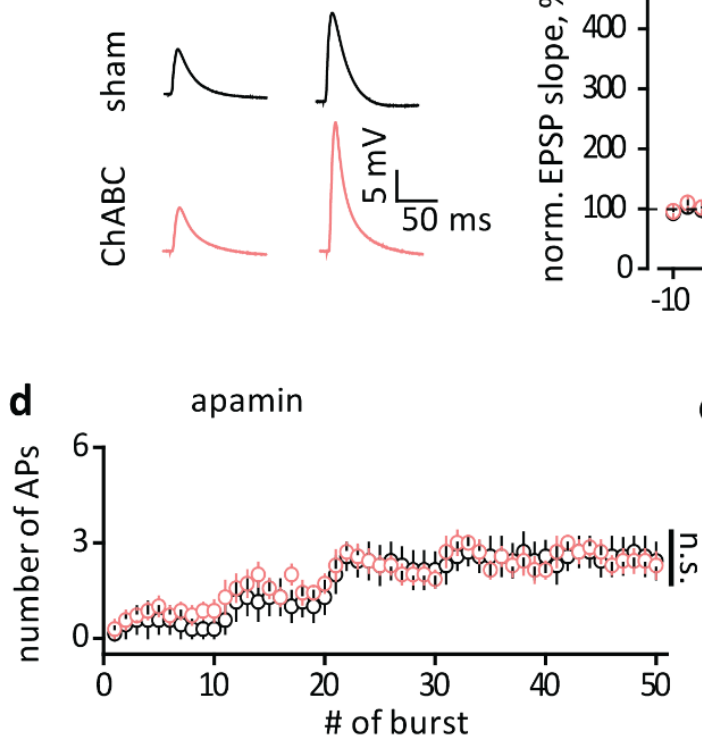

f apamin, Y-27632

baseline after TBS

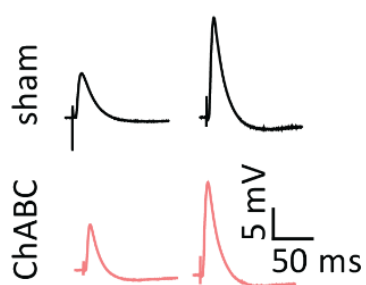

b

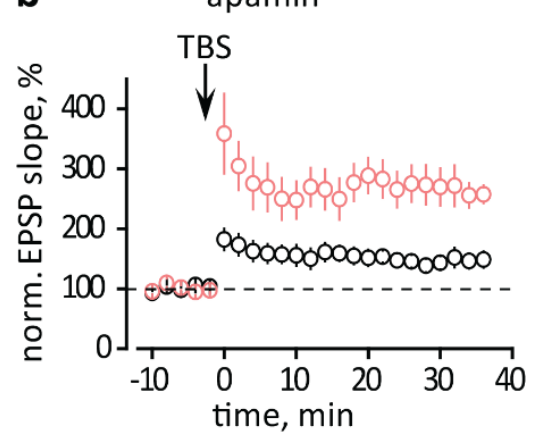

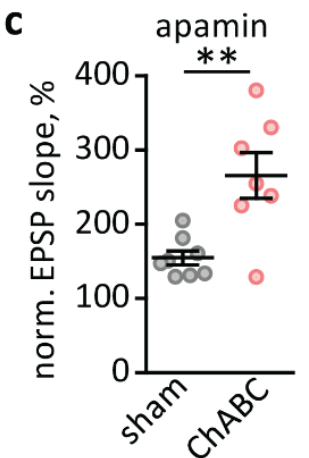

e

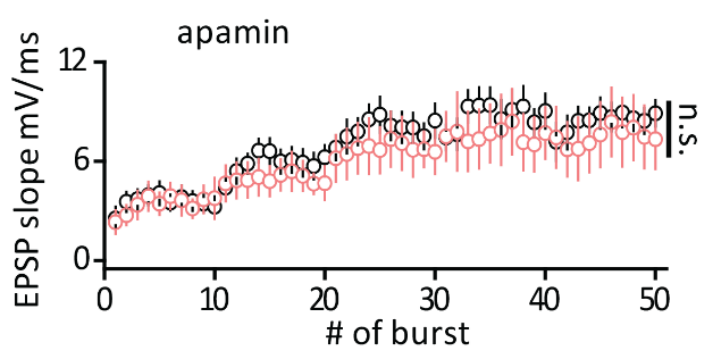

g

apamin, Y-27632

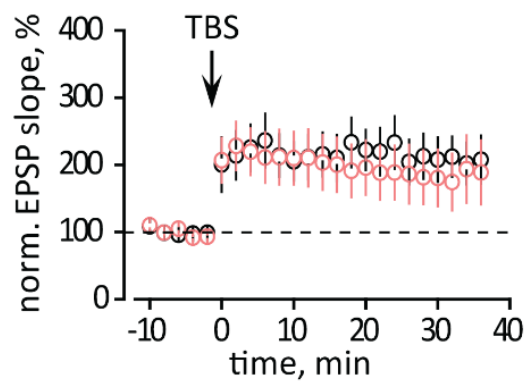

h apamin, $\mathrm{Y}-27632$

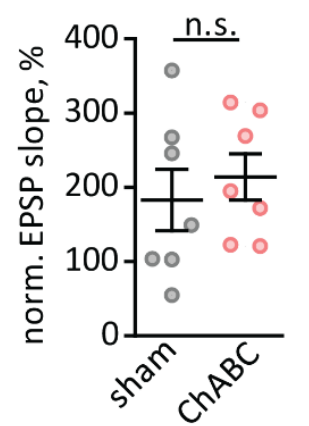

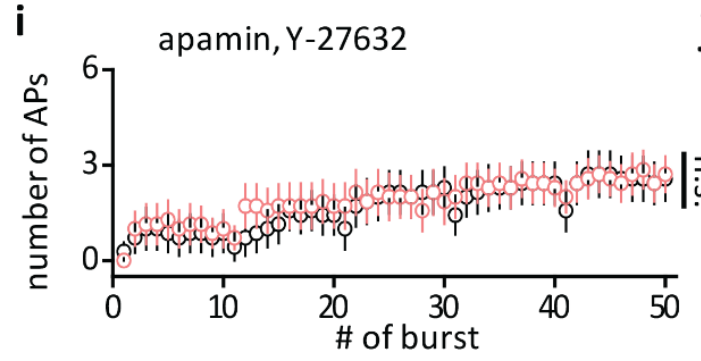

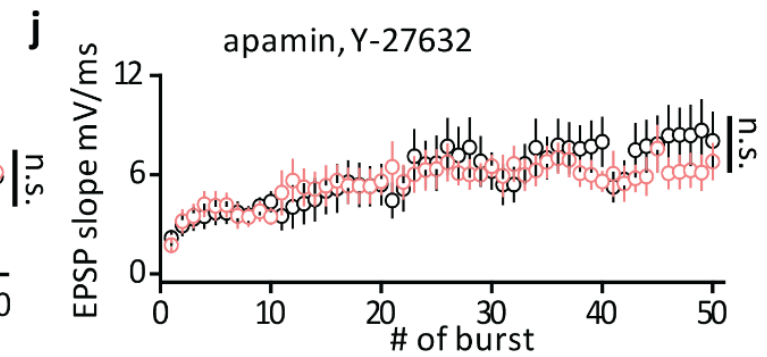

Figure 5. Blockade of SK channels reveals ROCK pathway-dependent enhancement of LTP

a. EPSPs recorded in CA1 pyramidal neurons before (baseline) and after TBS in the presence of apamin. b. The time-course of normalized EPSP slopes before and after TBS (arrow, zero time point) in the presence of apamin. c. LTP magnitudes averaged over the last 10 min of recordings presented in $b$. d,e. The number of action potentials (APs, $d)$ and the EPSP slope $(e)$ recorded in response to individual bursts during TBS used to induce LTP ( 5 series by 10 bursts) in the presence of apamin. $f$. EPSPs recorded in CA1 pyramidal neurons before (baseline) and after TBS in the 
bioRxiv preprint doi: https://doi.org/10.1101/2020.04.23.058115; this version posted May 3, 2020. The copyright holder for this preprint (which

was not certified by peer review) is the author/funder, who has granted bioRxiv a license to display the preprint in perpetuity. It is made available under aCC-BY-NC-ND 4.0 International license.

presence of apamin and the ROCK inhibitor Y-27632. g. The time-course of normalized EPSP slopes before and after TBS (arrow, zero time point) in the presence of apamin and Y-27632. $\mathbf{h}$. LTP magnitudes averaged over the last 10 min of recordings presented in $b$. $\mathbf{i}, \mathbf{j}$. The number of APs ( $i$ ) and the EPSP slope $(j)$ recorded in response to individual bursts during TBS used to induce LTP ( 5 series by 10 bursts) in the presence of apamin and Y-27632.

Black traces and circles - recordings in sham-treated slices; pink traces and circles - recordings in ChABC-treated slices. The data are presented as the mean \pm SEM. n.s. $p>0.05$; ${ }^{* *} p<0.01$; twotailed two-sample $t$-test (panels $c, h$ ); two-way RM ANOVA (panels $d, e, i, j$ ). 


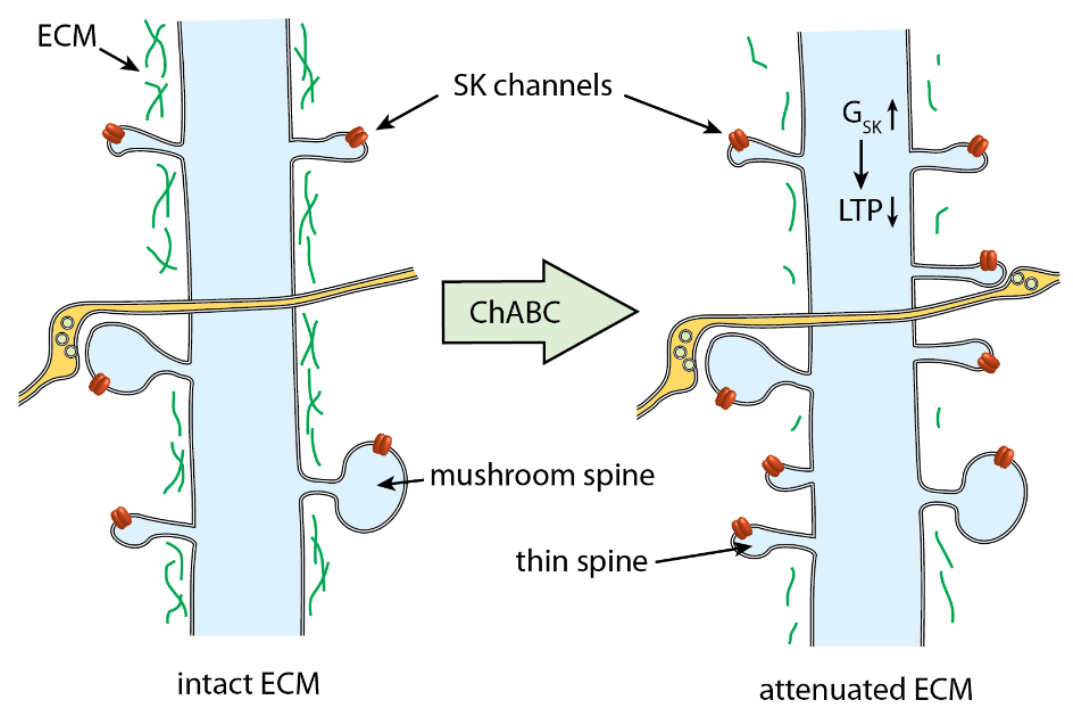

Figure 6. A schematic showing the effect of ECM attenuation on a dendrite of a CA1 pyramidal neuron

The ECM forms a meshwork (green) around the dendrite (blue), preventing the formation of new spines. When the ECM is attenuated with ChABC, new thin spines emerge. These spines form synaptic contacts with existing axons, Schaffer collaterals (yellow). The number of mature mushroom spines does not change. The appearance of new spines adds extra SK channels. An increase in the overall SK channel conductance $\left(G_{S K}\right)$ decreases neuronal excitability and suppresses LTP. 